\title{
The role of integrins in pulmonary fibrosis
}

\author{
D. Sheppard
}

ABSTRACT: Integrins are a large family of transmembrane glycoprotein receptors initially identified as mediators of cell adhesion and tissue integrity. However, it is now known that the primary function of integrins in mammals is to act as signalling proteins.

Signals from integrins are known to play critical roles in virtually every aspect of the behaviour of epithelial cells and in the development of certain pathological conditions, including pulmonary fibrosis. In this respect, the interaction between transforming growth factor- $\beta$, which is known to be pivotal in the development of pulmonary fibrosis, and the integrin $\alpha \mathrm{V} \beta 6$ is of particular interest.

Integrin $\alpha \mathrm{V} \beta 6$ is responsible for the activation of constitutively expressed latent transforming growth factor- $\beta$ by a mechanism that allows for temporal and spatial activity control.

There is increasing evidence that this mechanism plays a critical role in the pathological activity of transforming growth factor- $\beta$. Although other activation mechanisms have been identified, studies suggest that $\alpha \mathrm{V} \beta 6$-mediated activation of transforming growth factor- $\beta$ is necessary for the development of fibrosis in lung-disease models. The data from such studies imply that integrins may be attractive targets for intervention in pulmonary fibrotic diseases, such as idiopathic pulmonary fibrosis.

KEYWORDS: $\alpha \mathrm{V} \beta 6$, epithelial-to-mesenchymal transition, transforming growth factor- $\beta$

I ntegrins are a large family of heterodimeric transmembrane glycoprotein receptors, which have been shown to: mediate cell adhesion to a wide variety of extracellular matrix (ECM) proteins; mediate cell surface counter-receptors, including members of the immunoglobulin and cadherin families [1]; and mediate members of several other families, including growth factors [2] and proteases [3]. The maintenance of cell adhesion and tissue integrity is an important function for these receptors and is their major function in invertebrates. However, research has shown that the integrin family is far more complex in vertebrates, where they perform a range of important functions over and above their role in cell adhesion. In mammals, integrins act primarily as signalling proteins, transmitting a variety of signals involved in cell growth, division, survival, differentiation and apoptosis. Integrins do not contain any catalytic activity and do not independently initiate signalling cascades, but instead serve as scaffolds for the assembly of signalling complexes. Integrins are composed of a single $\alpha$ and a single $\beta$-subunit. In mammals, there are 18 human $\alpha$-subunits and eight $\beta$-subunits that can form a total of 24 integrin heterodimers (fig. 1) [4]. The organisation of the integrin family is similar in all mammals and varies only slightly in other vertebrates. Defects in transforming growth factor (TGF)- $\beta$ function are associated with a number of pathological states, including tumour cell growth, specific integrins have been shown to play a role in pulmonary fibrosis in various animal models or to have an important biological role that might contribute to pulmonary fibrosis. One such role involves their interaction with latent complexes of TGF- $\beta$.

\section{TGF- $\beta$}

There are three major isoforms of TGF- $\beta$ in mammals: TGF- $\beta 1,2$ and 3. All isoforms are similarly organised and activate similar signalling pathways in vitro but each has distinct in vitro effects, and knockouts of the genes encoding each isoform in mice result in widely divergent phenotypes [6-8]. TGF- $\beta$ is synthesised from a large precursor protein following cleavage of a signal peptide. Once in the secretory apparatus, this precursor protein is cleaved by an endoprotease, furin, and then assembled as two homodimers that are linked by disulfide bonds (fig. 2). The largest part of this protein is made up of the amino terminal fragment, which does not have cytokine activity and is known as the latency associated peptide (LAP); the shorter carboxy terminal fragment forms the active cytokine [9]. In the secretory apparatus of most cells this complex is assembled as a noncovalent association of these two homodimers. This is known as the small-latent complex because the active sites on the TGF- $\beta$ molecule are masked. It is usually autoimmune disease and fibrosis [5]. A number of
CORRESPONDENCE

D. Sheppard

University of California San Francisco UCSF Box 2922

San Francisco

CA 94143-2922

USA

Fax: 14155144278

E-mail: dean.sheppard@ucsf.edu

STATEMENT OF INTEREST

D. Sheppard is the co-owner of patents describing inhibition of the $\alpha \vee \beta 6$ integrin for the treatment of pulmonary fibrosis. He received funding through a sponsored research agreement from Biogen Idec for development and characterisation of monoclonal antibodies inhibiting $\alpha \vee \beta 6$ integrin function. 


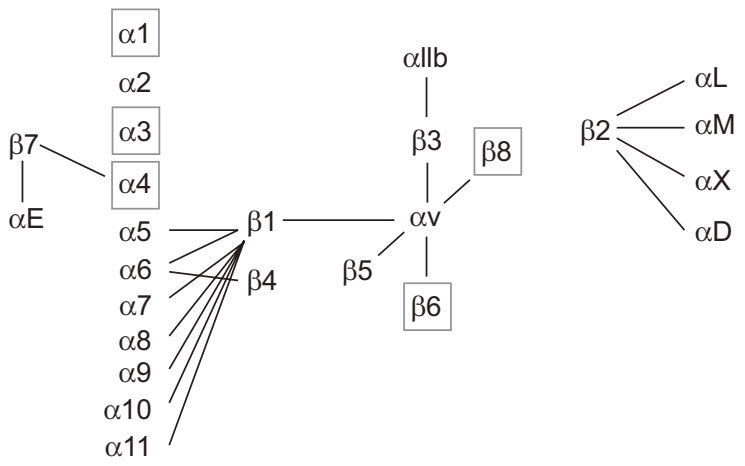

FIGURE 1. The mammalian integrin family. The solid lines indicate pairings that have been identified, to date, on mammalian cells. The boxes indicate integrins that are potentially involved in pulmonary fibrosis.

further associated with members of another family of gene products: the latent TGF- $\beta$ binding proteins. Four of these proteins have been identified in mammals, three of which are capable of forming a disulfide bond to LAP and are central to TGF- $\beta$ regulation [10]. This is the form in which TGF- $\beta$ is secreted from cells in the vast majority of cases, although there is some evidence that these complexes can also assemble extracellularly. The latent TGF- $\beta$ binding proteins target the latent complexes to the ECM, and are directly chemically crosslinked to the matrix via the action of an extracellular enzyme, tissue transglutaminase [11].

Most tissues, including the lung, contain significant quantities of latent TGF- $\beta$, and the amount of active TGF- $\beta$ this could generate is much higher than would be required to cause tissue damage; activation of only a small fraction of this latent TGF- $\beta$ is required to generate maximal cellular responses. The extracellular concentration of TGF- $\beta$ activity is primarily regulated by the conversion of latent TGF- $\beta$ to active TGF- $\beta$ and the reason that organisms normally survive without scarring of the lungs, kidneys, liver and other organs is the
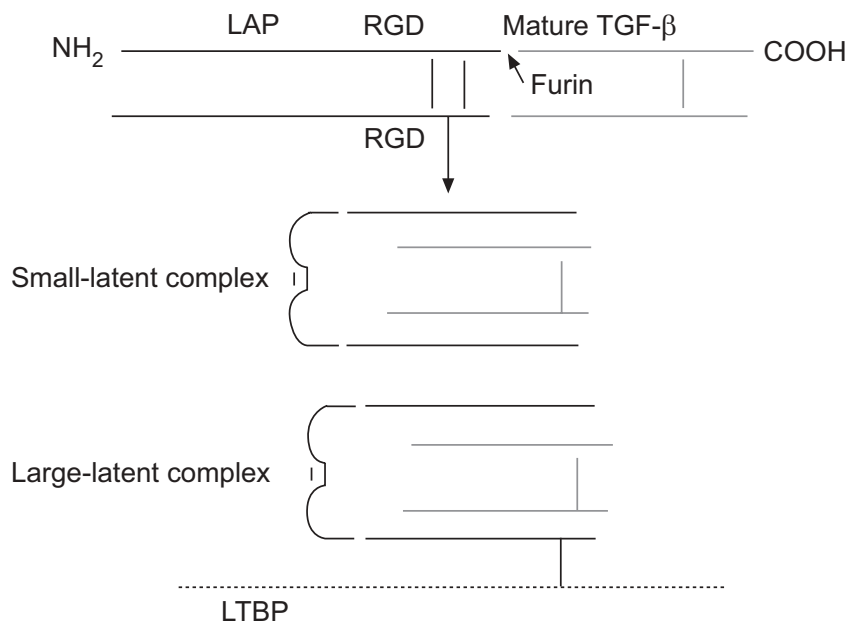

FIGURE 2. Synthesis of latent transforming growth factor (TGF)- $\beta$. LAP: latency associated peptide; RGD: tripeptide amino acid sequence of arginine, glycine and aspartic acid; LTBP: latent TGF- $\beta$ binding proteins. complex biological processes involved in this conversion. Overall, it would appear that although regulation of gene expression is involved in the regulation of the effects of TGF- $\beta$, this is a minor process which largely serves to maintain the tissue levels of latent TGF- $\beta$.

Early evidence for the mechanism behind latent TGF- $\beta$ activation came from examination of the amino acid sequence of the molecule by RuOSLAHTI and PIERSCHBACTER [12], who suggested that TGF- $\beta 1$ and 3 might interact with integrins because they both contain a linear tripeptide sequence of arginine, glycine, aspartic acid (RGD), which had been shown to be critical for the interaction of many members of the integrin family with their ligands. It is now know that this RGD sequence in TGF- $\beta 1$ and 3 is recognised by six different integrins, at least two of which perform the function of activating the latent complex, based on in vivo data. One of these is $\alpha \mathrm{V} \beta 6$, which is constituently expressed at low levels in many epithelial tissues, including alveolar epithelium. It is associated with latent TGF- $\beta$ through interaction with RGD sequence of latent TGF- $\beta$ binding protein, and is also a receptor for the ECM proteins fibronectin [13] and tenascin C [14]. Data suggest that $\alpha \mathrm{V} \beta 6$ is not important in the roles TGF- $\beta$ plays in development because mice lacking this integrin develop normally [15]. However, as discussed later, it plays a critical role in the pathological activity of TGF- $\beta$. A second integrin, $\alpha \mathrm{V} \beta 8$, also binds the same RGD sequence in latent TGF- $\beta$ but appears to activate TGF- $\beta$ in a completely different manner; this integrin has a different cytoplasmic domain on the $\beta 8$ subunit that does not appear to interact with cellular actin and is not required for the activation of TGF- $\beta$. In fact, $\alpha \mathrm{V} \beta 8$ appears to activate TGF- $\beta$ by presenting the latent complex to metalloproteases that cleave the LAP and release free TGF- $\beta$ [16]. $\alpha \mathrm{V} \beta 8$ is critical for vascular development, brain development and immune homeostasis [17, 18], but has not been shown to be important for the development of pulmonary fibrosis. Therefore, it is likely that it is $\alpha \mathrm{V} \beta 6$ which plays a role in the activation of TGF- $\beta$ associated with the pathogenesis of pulmonary fibrosis.

\section{INTEGRIN $\alpha \mathrm{V} \beta 6$ AND TGF $\beta \boldsymbol{\beta}$ ACTIVATION}

The first clue to the importance of $\alpha \mathrm{V} \beta 6$ in vivo came from mice homozygous for a null mutation in the gene encoding the $\beta 6$ subunit, effectively creating $\alpha \mathrm{V} \beta 6$ knockouts. Although $\alpha \mathrm{V} \beta 6$ was known to be expressed by epithelial cells, the phenotype seen in these mice was mostly mediated by leukocytes, with exaggerated inflammatory responses to injury in the lungs and skin. The responses in the skin included juvenile baldness associated with infiltration of macrophages into the skin in response to low-grade trauma. [15]. With regard to the lung, mice kept in normal conditions are exposed to environmental insults, such as ammonia off-gassing from their bedding. As a result, they developed dramatic inflammatory lung disease. Those kept in ventilated cages with reduced exposure to environmental injury developed significantly lower levels of inflammation in the lung. However, this inflammation is not associated with increased fibrosis in the bleomycin (BLM) model of pulmonary fibrosis. Although $\beta 6$ knockout mice show increased inflammation compared with wild-type mice in response to BLM, there is no increase in collagen deposition or fibrosis [2]. More recently, blocking antibodies to $\alpha \mathrm{V} \beta 6$ have 
been shown to prevent radiation-induced pulmonary fibrosis [19] and hepatic fibrosis induced by biliary obstruction [20].

The findings in these mice led to interest in a possible association with TGF- $\beta$, which had a well-established central role in tissue inflammation at multiple sites, including the lung. In addition, there was evidence that blocking antibodies to TGF- $\beta$ were able to prevent the development of BLMinduced fibrosis [21]. The role of $\alpha \mathrm{V} \beta 6$ and its association with TGF- $\beta$ was demonstrated using a co-culture bioassay system combining $\beta 6$-expressing cells and lung epithelial cells stably transfected with a highly TGF- $\beta$-sensitive reporter system composed of a portion of the plasminogen activator inhibitor-1 promoter driving expression of firefly luciferase [22]. Using this system, studies clearly demonstrated that $\alpha \mathrm{V} \beta 6$ induced TGF- $\beta$ activity, and that this effect could be equally well inhibited by antibodies to active TGF- $\beta 1$ or $\alpha \mathrm{V} \beta 6$ [2]. This effect was dependent on cell-cell contact and did not occur if the reporter cells and the integrin-expressing cells were separated by a filter that blocked cell contact while allowing passage of any free TGF- $\beta$, or if cells co-expressing reporter and integrin were diluted to the point at which cell-cell contact was eliminated [2]. This implies that the TGF- $\beta$ activated via $\alpha \mathrm{V} \beta 6$ remains bound and is not released as free cytokine. Instead, the integrin induces a conformational change in the latent complex which presents active cytokine to TGF- $\beta$ receptors in specific sites on adjacent cells. In addition, binding of the integrin is not sufficient to activate latent TGF- $\beta$ complexes. This process is probably regulated by a signalling pathway that involves close association of $\alpha \mathrm{V} \beta 6$ with the actin cytoskeleton in the integrinexpressing epithelial cell, with contraction of this cytoskeleton leading to the conformational changes seen on activation of latent TGF- $\beta$ [23]. Taken together with the fact that conformational change in the latent complex does not appear to release free active TGF- $\beta$ and the requirement for cell-cell contact, this pathway provides an elegant mechanism to tightly regulate the activity of this potent cytokine both in space and time.

The signals involved in initiating the activation of TGF- $\beta$ have not yet been fully defined. Recently, agonists of protease activated receptor (PAR)1, including thrombin, have been shown to activate TGF- $\beta$ in an $\alpha \mathrm{V} \beta 6$ integrin-specific manner [24]. This effect was found to be PAR1 specific and mediated via the small GTPase RhoA and its downstream effector, Rho kinase. The data from this study suggest a model in which activation of RhoA/ Rho kinase, which has well-known effects in reorganising actin, induces a change in cell shape that exerts a mechanical force on the latent complex, in turn inducing a conformational change that allows active TGF- $\beta$ to become available to adjacent cells [24]. Further evidence supporting this model comes from the fact that Rho kinase inhibitors completely block TGF- $\beta$ activation through this pathway [24]. This study provides some clues as to how the $\alpha \mathrm{V} \beta 6$-mediated TGF- $\beta$ activation pathway is activated itself and also indicates a number of targets for how it might be inhibited [24]. The next question to arise is whether there is evidence to suggest that $\alpha \mathrm{V} \beta 6$ is associated with the development of pulmonary fibrosis in humans.

\section{DISTRIBUTION OF $\alpha$ V $\beta 6$ IN PULMONARY FIBROSIS}

Upregulation of TGF- $\beta$ has been demonstrated in a variety of human inflammatory or fibrotic lung diseases. In addition, upregulation of $\alpha \mathrm{V} \beta 6$ has recently been demonstrated in lung tissue from patients with fibrosis due to scleroderma and with idiopathic pulmonary fibrosis (IPF; fig. 3) [25]. Intense staining was seen within both type II and type I pneumocytes lining the alveolar ducts and alveoli, whereas large airways were largely negative and intra-alveolar macrophages were negative. There was little, if any, apparent upregulation of $\alpha \mathrm{V} \beta 6$ in patients with scleroderma who had nonspecific interstitial pneumonia, whereas in patients with scleroderma who had usual interstitial pneumonia (UIP) or in patients with IPF and UIP, the expression of the integrin was dramatically upregulated [25]. These findings provide further evidence of a pivotal role for $\alpha \mathrm{V} \beta 6$ in TGF- $\beta$ activation and subsequent fibrosis in patients with pulmonary fibrosis.

\section{POTENTIAL FOR THERAPEUTIC INTERVENTION}

It is clear that TGF- $\beta$ has a central role in driving many of the pathological processes underlying pulmonary fibrosis. However, systemically altering TGF- $\beta$ expression may be difficult given its diverse activities and the importance of maintaining the delicate balance of its positive and negative effects. Disruption of this balance can contribute to aberrant development, malignancy, or pathogenic immune and inflammatory responses [26]. In fact, deletion of TGF- $\beta 1$ in mice is lethal due to widespread uncontrolled inflammation [27], and inhibition of TGF- $\beta$ in animal models leads to a range of complications including accelerated atherosclerosis [28, 29].

However, inhibition of $\alpha \mathrm{V} \beta 6$ offers the possibility of local inhibition of TGF- $\beta$ at sites of $\alpha \mathrm{V} \beta 6$ upregulation without affecting other homeostatic roles of TGF- $\beta$ [25]. In the BLM model, treatment with anti- $\alpha \mathrm{V} \beta 6$ monoclonal antibodies blocks the development of fibrosis, even if administered $\leqslant 14$ days after BLM administration [25]. As mentioned previously, mice lacking $\alpha \mathrm{V} \beta 6$ do not develop fibrosis, which also supports the blockage of $\alpha \mathrm{V} \beta 6$ as a potential target; however, these mice develop other major problems associated with an exaggerated inflammatory response, including emphysema and activation of macrophages with increased protease secretion. Therefore, the question is whether there is a reasonable therapeutic window that would allow inhibition of the integrin to block fibrosis or the development of pulmonary oedema, which might accompany acute exacerbations in IPF without causing these adverse affects.

In mice, the use of a blocking antibody to $\alpha \mathrm{V} \beta 6$ was able to reduce BLM-induced increases in collagen expression in a dose-dependent manner, with saturating inhibition and reduction of collagen deposition occurring at $\sim 1 \mathrm{mg} \cdot \mathrm{kg}^{-1}$ (fig. 4) [25]. At high doses $\left(\geqslant 10 \mathrm{mg} \cdot \mathrm{kg}^{-1}\right)$, there was increased expression of markers of inflammation and macrophage activation, consistent with the effects of TGF- $\beta$ inhibition in the lung. However, low doses of antibody were found to attenuate collagen expression without increasing either alveolar inflammatory cell populations or macrophage activation markers [25]. Overall, there was a 10-fold difference between the dose of antibody needed to be administered to block pulmonary fibrosis and the dose that caused protease induction, suggesting that the therapeutic window for anti- $\alpha \mathrm{V} \beta 6$ is reasonably wide, at least in the mouse model. Whether these findings can be translated into humans remains to be investigated. 

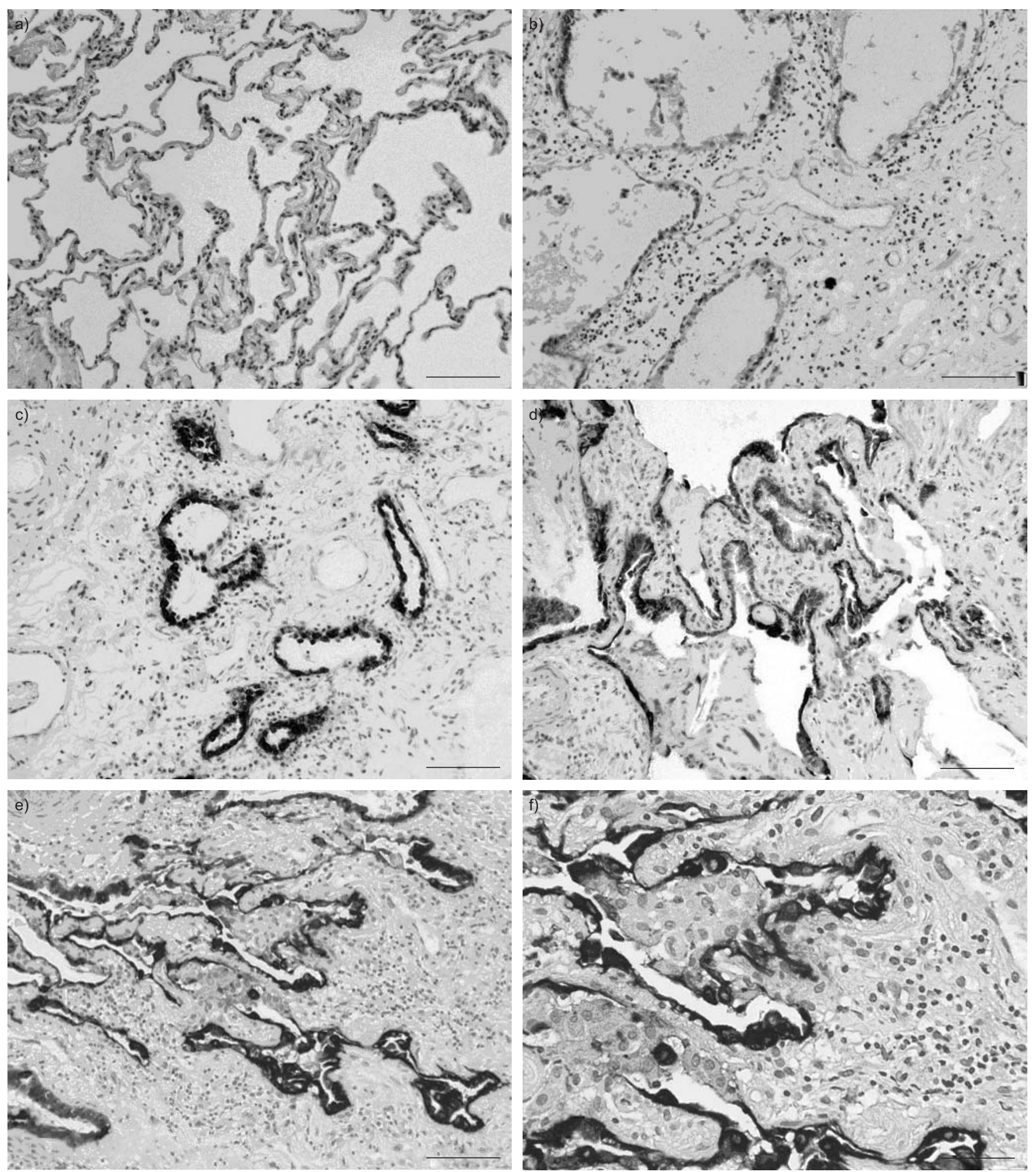

FIGURE 3. Immunohistochemical staining of pulmonary tissues for $\alpha \mathrm{V} \beta 6$ integrin expression in a) a healthy patient, b) systemic sclerosis with nonspecific interstitial pneumonitis, $c$ and d) systemic sclerosis with usual interstitial pneumonitis, and e and f) idiopathic pulmonary fibrosis with usual interstitial pneumonitis. Cells expressing $\alpha$ V $\beta 6$ integrin appear darker. Nuclei were counterstained with haematoxylin and eosin. a-e) Scale bars $=100 \mu \mathrm{m}$, f) scale bar=50 $\mu \mathrm{m}$. Reproduced from [25] with permission from the publisher. 


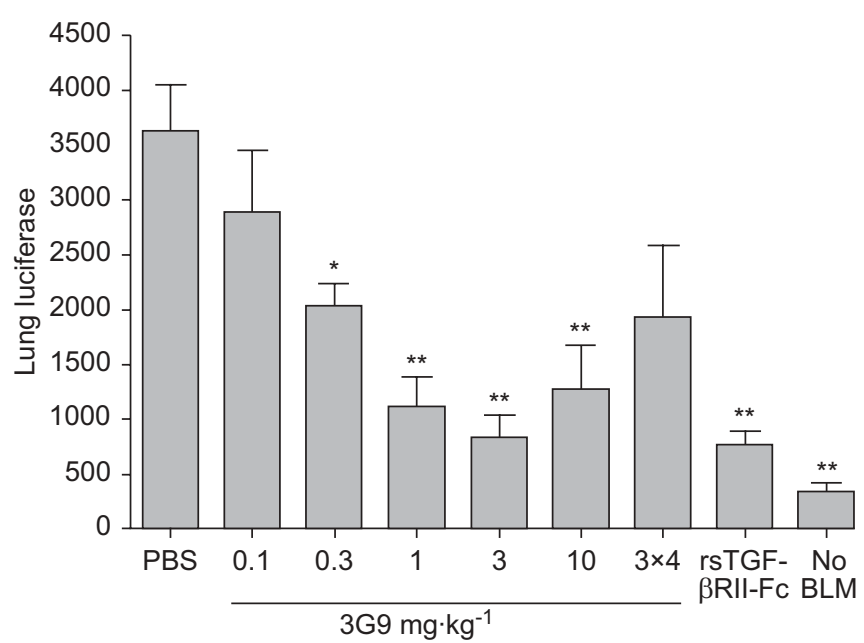

FIGURE 4. Bleomycin (BLM)-induced collagen expression can be decreased in a dose-dependent manner in response to treatment with $3 G 9$, a murine anti- $\alpha$ V $\beta 6$ monoclonal antibody. rsTGF- $\beta R I I-F c$ : recombinant soluble murine transforming growth factor (TGF)- $\beta$ receptor type $\|-F_{C}$ fusion protein (a positive control for inhibition of TGF- $\beta 1$ ); $3 \times 4$ : mice treated three times weekly with $4 \mathrm{mg} \cdot \mathrm{kg}^{-1}$. Reproduced from [25] with permission from the publisher.

\section{aVß6 AND EPITHELIAL-TO-MESENCHYMAL TRANSITION DURING PULMONARY FIBROSIS}

Alveolar epithelial-to-mesenchymal transition (EMT) has been shown to occur in vitro and has been proposed to be a source of fibroblasts during pulmonary fibrogenesis. КIM et al. [30] developed a triple transgenic mouse reporter system in which lung epithelial cells were genetically altered to permanently express the reporter $\beta$-galactosidase ( $\beta$-gal). This system allowed the fate of these cells to be mapped and enabled definitive testing of whether EMT occurs in vivo in an animal model of pulmonary fibrosis, i.e. overexpression of active TGF- $\beta 1$ [30]. Within 3 weeks of in vivo TGF- $\beta 1$ expression, $\beta$-gal-positive cells expressing mesenchymal markers accumulated in the injured lungs. The vast majority of vimentin-positive cells were $\beta$-gal positive, demonstrating that epithelial cells were the main source of mesenchymal expansion in response to TGF- $\beta$ in this model [30].

Interestingly, EMT could be driven in vitro without the need for treatment with TGF- $\beta$ if primary alveolar epithelial cells were cultured on provisional matrix components, fibronectin or fibrin. In this system, epithelial cells undergo robust EMT via integrin-dependent activation of endogenous latent TGF$\beta 1$. In contrast, primary cells cultured on laminin/collagen mixtures do not activate latent TGF- $\beta 1$ and undergo apoptosis rather than EMT if exposed to active TGF- $\beta 1$ [30]. Interestingly, this phenomenon does not occur if epithelial cells from $\beta 6$ knockout mice are used where there is no EMT in response to provisional matrix components. Taken together, these data demonstrate the importance of alveolar epithelial cells as progenitors for fibroblasts in vivo and implicate the provisional $\mathrm{ECM}$ and integrin $\alpha \mathrm{V} \beta 6$ as key regulators of epithelial transdifferentiation during fibrogenesis.

\section{CONCLUSION}

To summarise, the data discussed suggest a model in which epithelial injury and subsequent activation of a number of possible receptor pathways activate the small amount of $\alpha \mathrm{V} \beta 6$ which is constitutively expressed on alveolar epithelial cells to activate bound latent TGF- $\beta$. In turn, active TGF- $\beta$ increases $\alpha v \beta 6$ expression on alveolar epithelial cells and also induces production of a provisional matrix. TGF- $\beta$ in the presence of a provisional matrix, but not normal basement membrane, supports the process of EMT and, in the presence of active TGF- $\beta$, the fibroblasts that are induced by this process initiate and sustain the development of fibrosis. There are a number of levels of positive feedback in this model which, once induced to a particular extent, could allow the process to continue to oscillate at a much higher frequency than would occur in normal wound repair and subsequently lead to the characteristic pattern of progressive fibrosis in diseases such as IPF.

Currently, data regarding the importance of $\alpha \mathrm{V} \beta 6$ and $\alpha \mathrm{V} \beta 6$ induced transforming growth factor- $\beta$ activation in pulmonary fibrosis are largely available from murine models. Whether this particular integrin is also critical in humans remains to be determined, but studies showing it is strongly upregulated in fibrotic human lung diseases suggest that it may indeed play an important role in driving pathological fibrosis.

\section{REFERENCES}

1 Cepek KL, Shaw SK, Parker CM, et al. Adhesion between epithelial cells and $\mathrm{T}$ lymphocytes mediated by E-cadherin and the $\alpha E \beta 7$ integrin. Nature 1994; 372: 190-193.

2 Munger JS, Huang $X$, Kawakatsu $H$, et al. The integrin $\alpha v \beta$ 6 binds and activates latent TGF- $\beta 1$ : a mechanism for regulating pulmonary inflammation and fibrosis. Cell 1999; 96: 319-328.

3 Brooks PC, Strromblad S, Sanders LC, et al. Localization of matrix metalloproteinase MMP-2 to the surface of invasive cells by interaction with integrin $\alpha v \beta 3$. Cell 1996; 85: 683-693.

4 Hynes RO. Integrins: bidirectional, allosteric signaling machines. Cell 2002; 110: 673-687.

5 Blobe GC, Schiemann WP, Lodish HF. Role of transforming growth factor- $\beta$ in human disease. N Engl J Med 2000; 342: $1350-1358$.

6 Kulkarni AB, Huh CG, Becker D, et al. Transforming growth factor- $\beta 1$ null mutation in mice causes excessive inflammatory response and early death. Proc Natl Acad Sci USA 1993; 90: 770-774.

7 Kaartinen V, Voncken JW, Shuler C, et al. Abnormal lung development and cleft palate in mice lacking TGF- $\beta 3$ indicates defects of epithelial-mesenchymal interaction. Nat Genet 1995; 11: 415-421.

8 Sanford LP, Ormsby I, Gittenberger-de Groot AC, et al. TGF- $\beta 2$ knockout mice have multiple developmental defects that are non-overlapping with other TGF- $\beta$ knockout phenotypes. Development 1997; 124: 2659-2670.

9 Sheppard D. Transforming growth factor- $\beta$ : a central modulator of pulmonary and airway inflammation and fibrosis. Proc Am Thorac Soc 2006; 3: 413-417.

10 Rifkin DB. Latent transforming growth factor- $\beta$ (TGF- $\beta$ ) binding proteins: orchestrators of TGF- $\beta$ availability. J Biol Chem 2005; 280: 7409-7412.

11 Nunes I, Gleizes PE, Metz CN, Rifkin DB. Latent transforming growth factor- $\beta$ binding protein domains involved in activation and transglutaminase-dependent 
cross-linking of latent transforming growth factor- $\beta$. J Cell Biol 1997; 136: 1151-1163.

12 Ruoslahti E, Pierschbacher MD. New perspectives in cell adhesion: RGD and integrins. Science 1987; 238: 491-497.

13 Busk M, Pytela R, Sheppard D. Characterization of the integrin $\alpha \mathrm{v} \beta 6$ as a fibronectin-binding protein. J Biol Chem 1992; 267: 5790-5796.

14 Prieto AL, Edelman GM, Crossin KL. Multiple integrins mediate cell attachment to cytotactin/tenascin. Proc Natl Acad Sci USA 1993; 90: 10154-10158.

15 Huang $\mathrm{XZ}, \mathrm{Wu} \mathrm{JF}$, Cass $\mathrm{D}$, et al. Inactivation of the integrin $\beta 6$ subunit gene reveals a role of epithelial integrins in regulating inflammation in the lung and skin. J Cell Biol 1996; 133: 921-928.

$16 \mathrm{Mu} \mathrm{D}$, Cambier S, Fjellbirkeland L, et al. The integrin $\alpha \mathrm{V} \beta 8$ mediates epithelial homeostasis through MT1-MMPdependent activation of TGF- $\beta 1$. J Cell Biol 2002; 157: 493-507.

17 Zhu J, Motejlek K, Wang D, Zang K, Schmidt A, Reichardt LF. $\beta 8$ integrins are required for vascular morphogenesis in mouse embryos. Development 2002; 129: 2891-2903.

18 Travis MA, Reizis B, Melton AC, et al. Loss of integrin $\alpha \mathrm{V} \beta 8$ on dendritic cells causes autoimmunity and colitis in mice. Nature 2007; 449: 361-365.

19 Puthawala K, Hadjiangelis N, Jacoby SC, et al. Inhibition of integrin $\alpha \mathrm{V} \beta 6$, an activator of latent transforming growth factor- $\beta$, prevents radiation-induced lung fibrosis. Am J Respir Crit Care Med 2008; 177: 82-90.

20 Wang B, Dolinski BM, Kikuchi N, et al. Role of $\alpha v \beta 6$ integrin in acute biliary fibrosis. Hepatology 2007; 46: 1404-1412.

21 Giri SN, Hyde DM, Hollinger MA. Effect of antibody to transforming growth factor- $\beta$ on bleomycin induced accumulation of lung collagen in mice. Thorax 1993; 48 959-966.

22 Abe M, Harpel JG, Metz CN, Nunes I, Loskutoff DJ, Rifkin DB. An assay for transforming growth factor- $\beta$ using cells transfected with a plasminogen activator inhibitor-1 promoter-luciferase construct. Anal Biochem 1994; 216: 276-284.

23 Sheppard D. Integrin-mediated activation of transforming growth factor- $\beta 1$ in pulmonary fibrosis. Chest 2001; 120 : Suppl. 1, 49S-53S.

24 Jenkins RG, Su X, Su G, et al. Ligation of protease-activated receptor 1 enhances $\alpha \mathrm{V} \beta 6$ integrin-dependent TGF- $\beta$ activation and promotes acute lung injury. J Clin Invest 2006; 116: 1606-1614.

25 Horan GS, Wood S, Ona V, et al. Partial inhibition of integrin $\alpha \mathrm{V} \beta 6$ prevents pulmonary fibrosis without exacerbating inflammation. Am J Respir Crit Care Med 2008; 177: 56-65.

26 McCartney-Francis NL, Frazier-Jessen M, Wahl SM. TGF- $\beta$ : a balancing act. Int Rev Immunol 1998; 16: 553-580.

27 Shull MM, Ormsby I, Kier AB, et al. Targeted disruption of the mouse transforming growth factor- $\beta 1$ gene results in multifocal inflammatory disease. Nature 1992; 359: 693-699.

28 Mallat Z, Gojova A, Marchiol-Fournigault C, et al. Inhibition of transforming growth factor- $\beta$ signaling accelerates atherosclerosis and induces an unstable plaque phenotype in mice. Circ Res 2001; 89: 930-934.

29 Robertson AK, Rudling M, Zhou X, Gorelik L, Flavell RA, Hansson GK. Disruption of TGF- $\beta$ signaling in T cells accelerates atherosclerosis. J Clin Invest 2003; 112: 1342-1350.

30 Kim KK, Kugler MC, Wolters PJ, et al. Alveolar epithelial cell mesenchymal transition develops in vivo during pulmonary fibrosis and is regulated by the extracellular matrix. Proc Natl Acad Sci USA 2006; 103: 13180-13185. 